\title{
ERRATUM
}

Tie-Jun Liu • Yue-Sheng Wang • Chuanzeng Zhang

\section{Axisymmetric frictionless contact of functionally graded materials}

Published online: 29 April 2008

(c) Springer-Verlag 2008

\section{Erratum to: Arch Appl Mech (2008) 78:267-282 \\ DOI 10.1007/s00419-007-0160-y}

We regret that the referenced paper contains some errors. The results shown in Figs. 7 and 9 are for $R / h_{0}=1$ instead of $R / h_{0}=10$. The results presented in Fig. 10 are for the spherical indenter instead of the conical one. The corresponding results for latter are shown here in Fig. 1. We apologize for any inconvenience caused by our mistakes.
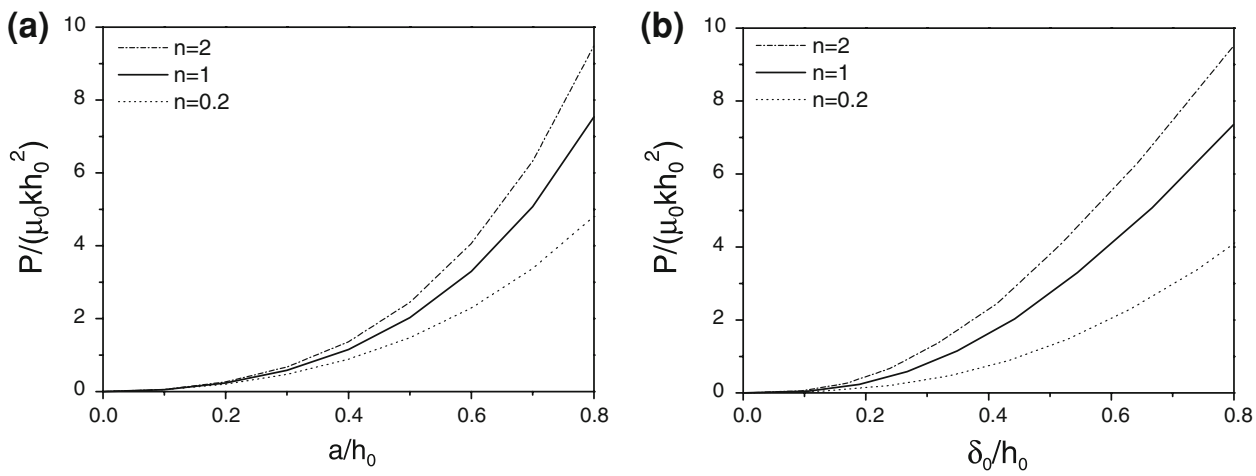

Fig. 1 Relation of $P$ versus $a$ (a) and $P$ versus $\delta_{0}$ (b) for selected values of $n$, the conical indenter

The online version of the original article can be found under doi:10.1007/s00419-007-0160-y.

T.-J. Liu · Y.-S. Wang ( $\varangle)$

Institute of Engineering Mechanics, Beijing Jiaotong University, Beijing 100044, China

E-mail: yswang@bjtu.edu.cn

Tel.: +86-10-51688417

Fax.: +86-10-51682094

C. Zhang

Department of Civil Engineering, University of Siegen, 57068 Siegen, Germany 